\title{
SOME OBSERVATIONS ON SOCIOLINGUISTIC VARIATION \\ AND AMERICAN SIGN LANGUAGE
}

JAMES C. WOODWARD, JR.

Linguistics Research Laboratory

Gallaudet College

This paper attempts to make a case for the value of studying linguistic and social structures in the U.S. deaf community (and other communities) in a dynamic sociolinguistic framework by presenting a brief outline of the language situation in the deaf community, some specific facts on linguistic variation in the deaf community, the correlation of the linguistic variation with selected social variables, and the relevance of this kind of research to sociology and the deaf community.

\section{Introduction}

As Labov (1970) has pointed out, the field known as sociolinguistics has three branches: 1) the sociology of language, 2) the ethnography of communication, and 3) linguistics. Fishman (1968) is a good example of the sociology of language-the use of sociolinguistics to solve sociological questions. Hymes $(1964,1968)$ typifies the approach to language and society known as the ethnography of communication-the use of sociolinguistics to view language in a larger, holistic framework of communication within and between societies. Linguists have been extremely interested in using sociolinguistics to solve linguistic questions.

Being a linquist, my main interest has been the linguistic branch of sociolinguistics. However, I believe my work is also of value to the sociologist. My work has been primarily with linguistic variation in the deaf community in the United States. This area of research is crucial for the linguist, the sociologist, and the deaf themselves, since the deaf have been looked on as physically, socially, and linguistically pathological. While it is true that there is a physical pathology, claims for social and linguistic pathology are actually no more than ethnocentric compulsions of one social group (the hearing) towards another (the deaf) (see Markowicz, 1972).

The deaf community is a fertile testing ground for linguistic (Bellugi and Fischer, 1972) and sociological (Meadow, 1972) theories, since the deaf community is in some special ways unique. The primary languages in the deaf community are channeled through a visual-manual mode, and as Hymes (1964) has pointed out, changes in channel can result in radical changes in codes and code structures. As far as social aspects of the deaf community are concerned, only ten percent of deaf children are born of deaf parents. For the majority of the deaf, transmission of deaf culture takes place in state residential schools for the deaf. This transmission generally first takes place from deaf children of deaf parents to other deaf children, since deaf children rarely have a deaf teacher until high school. 
This paper attempts to make a case for the value of studying linguistic and social structures in the U.S. deaf community in a dynamic sociolinguistic framework by presenting (1.0) a brief outline of the language situation in the deaf community, (2.0) some specific facts on linguistic variation in the deaf community, $(3.0)$ the correlation of the linguistic variation with selected social variables and $(4.0)$ the relevance of this kind of research to sociology and the deaf community.

\section{The Deaf Diglossic Continuum}

1.1 The Deaf Community. Croneberg (1965) and Meadow (1972) have pointed out that the deaf form a minority community in the United States. The deaf as a group are held together by language, clubs, social organizations, etc. (Meadow, 1972). She states:

The group definition is strengthened further with the knowledge that deaf persons are characterized by endogamous marital patterns. In the survey of the deaf population of New York State, for example, it was found that only 5 percent of women born deaf, and about 9 percent of women who became deaf at an early age, were married to hearing men (Rainer, et al., 1963: 17). Voluntary associations include a National Association of the Deaf with many thousands of members and a semi-monthly publication, The Deaf American. In addition most states have subsidiary associations with the publications of their own. State residential schools for the deaf form a nation-wide network that supports the cohesiveness of the sub-culture and promotes language. Also in existence is a national deaf sports organization that sends delegates to the World Deaf Olympics, a deaf fraternal order with the primary purpose of offering special insurance for members, and innumerable local deaf social clubs and sports teams (Meadow, 1972: 2-3).

But just as not all Blacks belong to the U.S. Black subculture, not all the deaf belong to the deaf subculture. They must be enculturated or acculturated into the deaf community. Meadow points out that this socialization into the language and culture of the deaf community may take place at several times during the life of a deaf person. Meadow (1972: 14) writes, "There are (1) infancy; (2) the time of enrollment in a residential school for the deaf (probably between the ages of five and thirteen); (3) the time of graduation from high school." She later points out that deaf children of deaf parents generally are socialized into the deaf community at infancy and that deaf children of hearing parents are generally socialized at stage 2 or 3. But socialization into the deaf community invariably includes acquisition of some variety or varieties of language used by the deaf community.

1.2 Sign Language Diglossia. The language situation that acts as a cohesive force in the deaf community is a diglossic situation. Stokoe (1970) first pointed out the existence of diglossia in the deaf community, using Ferguson's (1959) classic paper on diglossia as a model. Stokoe defined the High $(H)$ variety as Manual English and the Low (L) variety as American Sign Language. Manual English is a combination of signs and fingerspelling that represents a morpheme to morpheme correlation with spoken English. An example of this is:

$$
[] I^{\text {II }} \text { WENT } G_{T P} G_{1}^{\times} \text {THE } Q_{V} O_{v} \hat{I}
$$


"I went to the store" where "I" is signed, "went" is fingerspelled, "to" is signed, "the" is fingerspelled, and "store" is signed. All of these morphemes could be spelled and this would be what is known as the Rochester Method. American Sign Language is a language in and of itself. It has a different grammatical structure from English and has little, if any, fingerspelling. For example, English “Have you been to California?”, which is Auxiliary, Subject, Verb, Locational Prepositional Phrase, is translated into American Sign Language as:

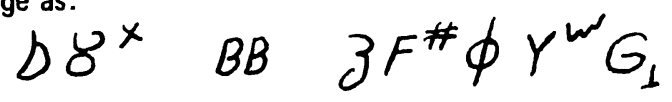

"Touch finish California you?", which is Verb, Auxiliary, Locational Noun, Subject, and Question, where Subject and Question are signed simultaneously.

Stokoe, in the same article, also demonstrated that Manual English (H) and American Sign Language (L) have the sociolinguistic characteristics that languages in diglossic situations have. $H$ is used in formal conversations, such as in church, the classroom, lectures, etc. $L$ is used in smaller, less formal, more intimate conversations. $H$ is considered superior to $L$, and $L$ is generally regarded as ungrammatical or nonexistent. Signers generally feel that "grammatical" $H$ should be used instead of $L$ for teaching. Some feel that standardization is necessary, but sign language diglossia appears as stable as other diglossic situations.

The diglossic situation that Stokoe is describing is not the "classical" diglossic situation, since as Ferguson (1959, 1972) has pointed out, the language varieties in diglossia that he was describing were actually varieties of the same language. However, Ferguson (1972) has also stated that although he does not particularly agree with the use of diglossia for situations where varieties of two different languages are involved, Fishman and others, e.g., Stokoe, are using diglossia to refer to these situations. Stokoe (1973) has proposed a two-dimensional diglossic model for the U.S. deaf community which seems to be more descriptive and explanatory of the deaf language situation.

1.3 The Diglossic Continuum. Stokoe's (1970) treatment of diglossia in the deaf community concentrated primarily on the extreme ends of the diglossic situation. In actuality, there is a continuum existing between varieties of Manual English and American Sign Language (Stokoe, 1972, 1973; Woodward, 1972, 1973a; and Moores, 1973). Intermediate varieties on the continuum have received various names: Deaf Non-standard English (Woodward, 1972), Signed English (O'Rourke, 1970), and Siglish (Fant, 1972).

Examples of Deaf Non-standard English are found in the written English of the deaf. These well-known linguistic variables are commonly known as "errors" or "poor English" in deaf education, just as Black English has been called "poor English" by some educators. Some of these variables are deletion and/or hypercorrection of articles, "he is humorous sport" or "I have a bread"; deletion of third person singular $s$ "he go to store" and others. Because of the negative reactions of earlier educators to what seems to be Deaf Non-standard English, we know little about social variables that may condition this linguistic variation. Undoubtedly some social variables are: social class, educational level of parents and self, date and degree of hearing loss of parents and self, whether the type of school attended was manual or oral, and probably a number of other factors. 
Pidgin Sign English (Woodward, 1972, 1973b) is another term for O'Rourke's (1970) Signed English and Fant's (1972) Siglish. Sometimes people sign something that seems to be a pidginized version of English. The syntactic order is primarily English, but inflections have been reduced in redundancy, and there is a mixture of American Sign Language and English structure. This pidgin seems always to be a second language, as expected of a pidgin, and is used only in restricted situations.

An example of this pidgin is:

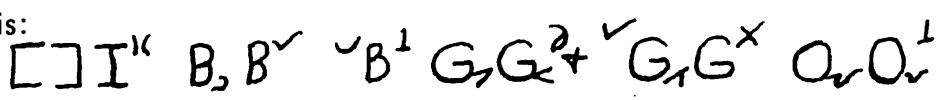

"I finish been go to the store." "Finish" is an American Sign Language aspect marker, "been" is an English word that is either spelled or signed (note there is no copula or progressive "be" in American Sign Language, so this is a purely English construction), and "go" has the "ing" deleted.

Moores (1972) has also suggested the possibility that some varieties of Home Signs may well also be on the deaf diglossic continuum. He states: "At the lowest level a system might consist of home-made gestures invented and understood perhaps by only one class of six or even seven students in a classroom excluding parents, teachers, and even other deaf students in the same program" (Moores, 1973: 3). No studies have been done on Home Signs to date, so it is not known whether Home Signs constitute a developing linguistic system with duality of patterning and semantactic rules of its own, or whether it is merely a system of naming. With all the prejudices against studying a more or less standard variety of American Sign Language, one can easily see why Home Signs have been ignored, although one can hardly excuse such an attitude.

2.0 Linguistic Variation in American Sign Language. To handle the complex variation in language continuums, sociolinguists DeCamp (1968), Bailey (1971), and Bickerton (1972) have been making use of Guttman's (1944) scalogram analysis as a preliminary to incorporating variation into grammars. These linguists and others feel that much of what has been termed free variation is in actuality describable in terms of implications. From implicational charts, weightings (relative importances) of phonological and/or semantic features that promote or inhibit operation of the linguistic rule can be discovered. In such an implicational model, given a set of features, A, B, C, D, these may be arranged in such an order that $A>B>C>D$. This means that if a lect has feature $A$, it will also have $B, C$ and $D$; if it does not have $A$ but has $B$, it will have $C$ and $D$; and so on. (Some linguists, e.g., Bailey [1971], have proposed the use of the term lect instead of dialect because a real dialect, i.e., a speech community bounded by isogloss bundles, is rarely found.) For a set of four features there are sixteen possible lectal arrangements $\left(2^{4}\right)$. However, most features and rules seem to be implicationally ordered, and so according to the logic of the implicational model, there can be only five lects $(4+1 ;$ or $A B C D, B C D, C D, D$, and none of these). Languages tend not to have the mathematically possible number of lects; languages do tend to have lects that can be described in terms of the implicational model. The mathematical (possible) and the implicational arrays of lects with four hypothetical features are shown in Tables 1 and 2.

Woodward (1973a) showed that the operation of at least three grammatical rules in American Sign Language and at least two grammatical rules in Signed English can be described implicationally and can be correlated with selected social variables (see section 3.0). However, only one of these linguistic variables, verb reduplication in ASL, will be discussed in this paper. 
Table 1. Mathematically Possible Arrangement of Four Features (+, Presence; -, Absence) in Lects.

$\begin{array}{rrrrrrrrrrr} & \text { A } & \text { B } & \text { C } & \text { D } & & \text { A } & \text { B } & \text { C } & \text { D } \\ 1 & + & + & + & + & 9 & - & + & + & + \\ 2 & + & + & + & - & 10 & - & + & + & - \\ 3 & + & + & - & + & 11 & - & + & - & + \\ 4 & + & + & - & - & 12 & - & + & - & - \\ 5 & + & - & + & + & 13 & - & - & + & + \\ 6 & + & - & + & - & 14 & - & - & + & - \\ 7 & + & - & - & + & 15 & - & - & - & + \\ 8 & + & - & - & - & 16 & - & - & - & -\end{array}$

Table 2. Lects Possible With Four Features in Implicational Order

$\begin{array}{lllll} & \text { A } & \text { B } & \text { C } & \text { D } \\ 1 & + & + & + & + \\ 2 & - & + & + & + \\ 3 & - & - & + & + \\ 4 & - & - & - & + \\ 5 & - & - & - & -\end{array}$

2.1 Variation in ASL Verb Reduplication. Woodward (1973a) showed that nine verbs tested for verb reduplication patterned implicationally in the order: $G_{n}^{\prime} G_{\Lambda}^{x}$ 'meet' $\geqslant S_{1}^{\prime}$ 'memorize' $>L_{T} V_{T}^{+}$'see' $C_{a} C_{a}^{T}$ 'want'

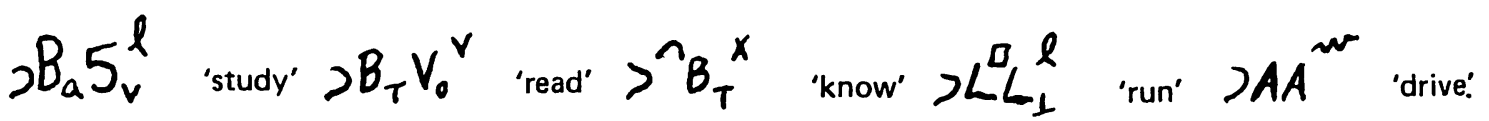

There are ten implicational lects based on this implication $(9+1)$ even though there are mathematically $356\left(2^{9}\right)$ possible lects. Table 3 shows the ten lects. With nine verbs and 141 informants, there was a total of 1269 possible responses. There were 119 exceptions to the implication, yielding a 9.4 percent rate for exceptions or a 10.6 percent rate of acceptability, indicating a valid implication. Guttman (1944) proposed 85 percent acceptability as valid; linguists, e.g., Baily (1973), prefer 89 percent acceptability. The information supplied by the implication can be incorporated into the grammar. However, methodology for doing this will not be discussed in this article, since this paper is not written for linguists. What I believe will interest sociologists more is the fact that linguistic variation in verb reduplication is correlated with social variables. 
Table 3. Verb Reduplication Implication

$\begin{array}{lccccccccc}\text { Lects } & \text { 'meet' } & \text { 'memorize' } & \text { 'see' } & \text { 'want' } & \text { 'study' } & \text { 'read' } & \text { 'know' } & \text { 'run' } & \text { 'drive' } \\ 1 & + & + & + & + & + & + & + & + & + \\ 2 & - & + & + & + & + & + & + & + & + \\ 3 & - & - & + & + & + & + & + & + & + \\ 4 & - & - & - & + & + & + & + & + & + \\ 5 & - & - & - & - & + & + & + & + & + \\ 6 & - & - & - & - & - & + & + & + & + \\ 7 & - & - & - & - & - & - & + & + & + \\ 8 & - & - & - & - & - & - & - & + & + \\ 9 & - & - & - & - & - & - & - & - & + \\ 10 & - & - & - & - & - & - & - & - & -\end{array}$

3.0 Correlation of Linguistic Variation with Social Variation. Most sociolinguists have attempted to correlate social class with linguistic variation. They have generally assumed that social class may be described by an inter-correlation of education, occupation, and income. Other factors such as age and sex have been shown to be correlated with linguistic variation (Wolfram, 1969; Trudgill, 1972).

I felt for the study of the deaf that four social variables might correlate well with variation in sign language. These variables were whether a person is \pm deaf, has \pm deaf parents, learned signs \pm before the age of six, and has \pm attended some college.

Basically there are two reasons for choosing these four variables over others. 1) I did not feel it was justified to assume social class was determined in the same way for both the hearing and the deaf communities. 2) It seems that the first three of these social variables are extremely important criteria for socialization into the deaf community. If a person is deaf, he can much more easily join the deaf community. Very few hearing people can really be considered part of the deaf community. As mentioned earlier, Meadow (1972) pointed out that socialization into the deaf community invariably includes language socialization. With the children of deaf parents this language socialization generally takes place from birth. With children of hearing parents it may take place at other times. However, the age of six seems to be a crucial time in first language acquisition. Quite possibly a person learning signs after the age of six will sign differently than a person who learned signs earlier.

The fourth variable, education, seems to be a universal social variable for those societies having a formal education system, since education tends to preserve and transmit traditional values toward language and society as well as to promote a maintenance of language forms and structures that may not be present in everyday conversation. 
As far as variation in verb reduplication is concerned, lects 1.5 in Table 3 are the lects that are closest to pure ASL on the deaf diglossic continuum, since they are the lects that accept verb reduplication in the most environments. Conversely, lects 6-10 in Table 3 are the lects that are the furthest from ASL on the continuum, since they are the lects that accept verb reduplication in the fewest environments. Thus, it is possible to test dependency relationships between each of the four social variables and membership in lects 1-5 (ASL-like lects) and lects 6-10 (Non-ASL-like lects) by setting up two-by-two charts and running chi-square tests on the data. Tables 4-7 show the relationship between lectal membership and each of the social variables.

Table 4. Lectal Membership vs. Deafness

$\begin{array}{lrr}\text { Lects } & + \text { Deaf } & - \text { Deaf } \\ 1-5 & 100 & 20 \\ 6-10 & 8 & 13\end{array}$

A chi-square test of this data shows a very strong dependency relationship (at the .005 level) of \pm deaf and membership in verb reduplication lects. One is more likely to find a deaf person in lects $1-5$ (closer to ASL) and more likely to find a hearing person in lects 6-10 (further from ASL).

Table 5. Lectal Membership vs. Parentage

$\begin{array}{lcc}\text { Lects } & \text { +Deaf Parents } & \text {-Deaf Parents } \\ 1-5 & 35 & 85 \\ 6-10 & 1 & 20\end{array}$

A chi-square test of this data shows a dependency relationship (at the .05 level) of \pm deaf parents and membership in verb reduplication lects. One is more likely to find a person with deaf parents in lects 1-5 (closer to ASL) and more likely to find a person with hearing parents in lects 6-10 (further from ASL).

Table 6. Lectal Membership vs. Age of Sign Acquisition

$\begin{array}{ccc}\text { Lects } & \text { +Before } 6 & \text {-Before } 6 \\ 1-5 & 73 & 47 \\ 6-10 & 3 & 18\end{array}$


A chi-square test of this data shows a very strong dependency relationship (at the .005 level) of \pm before six and membership in verb reduplication lects. One is more likely to find a person who learned signs before the age of six in lects $1-5$ (closer to $A S L$ ) and more likely to find a person who learned signs after the age of six in lects 6-10 (further from ASL).

Table 7. Lectal Membership vs. Education (Hearing informants are not included in this chart.)

$\begin{array}{lcr}\text { Lects } & + \text { College } & - \text { College } \\ 1-5 & 44 & 56 \\ 6-10 & 0 & 8\end{array}$

A chi-square of this data shows a dependency relationship (at the .05 level) between education of the deaf informants and membership in verb reduplication lects. One is more likely to find a person with some college in lects $1-5$, a person with no college education in lects 6-10.

4.0 The Relevance of Sociolinguistics to Sociology and the Deaf. Too little is really known about the deaf as a linguistic and social group. Traditional linguistics is not adequate to explain the complex linguistic variation that has been observed in the deaf community. Sociolinguistics (variation) theory is adequate for describing this variation. Linguistic sociolinguistic research among the deaf should open up more knowledge about the deaf as a subculture, since language is one of the most cohesive factors in the deaf community and variation in sign language has been shown to be correlated with social variables.

Here it is important to point out that by studying linguistic variation in the deaf community, one cannot only set up linguistic hierarchies but also hierarchies of social variables. We have seen that membership in verb reduplication lects correlates with the four social variables selected in Woodward (1973a). In the same study, it was found that these four social variables did not correlate with all the linguistic variation studied. The most important social variable for signing seemed to be deafness, which correlated with four out of five linguistic variables. The second most important variable seemed to be parentage, which correlated with three out of five linguistic variables. Education correlated with two of the linguistic variables, and age of sign language acquisition correlated with only one of the linguistic variables.

Sociolinguistic research thus can aid sociologists in discovering more about social stratification and interaction in the deaf community. Sociologists using their own traditional tools with the addition of sociolinguistic theory can approach the deaf community from another point of view than linguists and develop new insights into sociological and linguistic analysis.

Of course, what has been said about the deaf community is easily applied to other social groups. My reasons for choosing the deaf community as an example were twofold: 1) My recent research has been primarily with deaf sociolinguistics. 2) The deaf need more linguists and sociologists who can understand the complex interrelationships of language and social variables in the deaf community. Deaf awareness is beginning to bud. If it is to flourish, the deaf need the help of impartial scholars outside the hearing-controlled field of deaf education. 


\section{References}

Bailey, Charles-James N.

1971 "Variation and language theory." Unpublished manuscript.

Bellugi, Ursula and Susan Fischer

1972 "A comparison of sign and spoken language." Cognition 1: 173-200.

Bickerton, Derek

1972 The Structure of Polylectal Grammars. Georgetown University Monograph Series on Languages and Linguistics, No. 25.

Croneberg, Carl

1965 "Sign language dialects." Pp. 313-319 in William Stokoe, Carl Croneberg and Dorothy Casterline (eds.), A Dictionary of American Sign Language. Washington, D.C.: Gallaudet College Press.

DeCamp, David

1968 "Toward a generative analysis of a post-creole speech continuum." Pp. 349-370 in Dell Hymes (ed.), Pidginization and Creolization of Languages. Cambridge: Cambridge University Press.

Fant, Louie

1972 Ameslan. Silver Spring, Md.: National Association of the Deaf.

Ferguson, Charles

1959 "Diglossia." Word 15: 325-340.

1972 Personal communication.

Fishman, Joshua A. (ed.)

1968 Readings in the Sociology of Language. The Hague: Mouton.

Guttman, Louis

1944 "A basis for scaling qualitative data." American Sociological Review 9:139-150.

Hymes, Dell

1964 "Towards ethnographies of communication." In John Gumperz and Dell Hymes (eds.), The Ethnography of Communication. American Anthropologist special publication, 66,6: 1-34

1968 "The ethnography of speaking." In Joshua A. Fishman (ed.), Readings in the Sociology of Language. The Hague: Mouton.

Labov, William

1970 "The study of language in its social context." Studium Generale 23:30-87.

Markowicz, Harry

1972 "Some sociolinguistic considerations of American sign language." Sign Language Studies 1:15-41. 
Meadow, Kathryn

1972 "Sociolinguistics, sign language, and the deaf sub-culture." Pp. 19-33 in Terrence O'Rourke (ed.), Psycholinguistics and Total Communication: The State of the Art. Washington, D.C.: The American Annals of the Deaf.

Moores, Donald

1972 "Communication: some unanswered questions and some unquestioned answers." Pp. 1-10 in Terrence O’Rourke (ed.), Psycholinguistics and Total Communication: The State of the Art. Washington, D.C.: The American Annals of the Deaf.

O'Rourke, Terrence J.

1970 Quoted in "Cal conference on sign languages." The Linguistic Reporter 12,2:5-8

Ranier, J.D., K.Z. Altshuler and F.J. Kallmann (eds.)

1963 Family and Mental Health Problems in a Deaf Population. New York: New York State Psychiatric Institute, Columbia.

Stokoe, William C., Jr.

1970 "Sign language diglossia." Studies in Linguistics 21:27-41.

1972 Personal communication.

1973 "Sign syntax and human language capacity." Unpublished manuscript presented as a forum lecture at the 1973 Summer Institute in Linguistics.

Trudgill, Peter

1972 "Sex, covert prestige, and linguistic change in the urban British English of Norwich." Language in Society 1,2: 175-195.

Wolfram, Walter

1969 A Sociolinguistic Description of Detroit Negro Speech. Washington, D.C.: Center for Applied Linguistics.

Woodward, James C., Jr.

1972 "Implications for sociolinguistic research among the deaf." Sign Language Studies 1:1-7.

1973a Implicational Lects on the Deaf Diglossic Continuum. Washington, D.C.: Georgetown University, unpublished Ph.D. dissertation.

1973b "Pidgin sign English." Unpublished manuscript. 